\title{
Papous d'Éric Lafforgue et Almut Schneider
}

Isabelle Leblic

\section{OpenEdition}

\section{Journals}

Édition électronique

URL : http://journals.openedition.org/jso/1972

DOI : 10.4000/jso. 1972

ISSN : $1760-7256$

\section{Éditeur}

Société des océanistes

\section{Édition imprimée}

Date de publication : 15 décembre 2008

Pagination : 335-336

ISBN : 978-2-85430-012-3

ISSN : 0300-953x

Référence électronique

Isabelle Leblic, "Papous d'Éric Lafforgue et Almut Schneider », Journal de la Société des Océanistes [En ligne], 126-127 | Année 2008, mis en ligne le 10 septembre 2008, consulté le 24 septembre 2020. URL : http://journals.openedition.org/jso/1972 ; DOI : https://doi.org/10.4000/jso.1972

Ce document a été généré automatiquement le 24 septembre 2020.

(c) Tous droits réservés 


\title{
Papous d'Éric Lafforgue et Almut Schneider
}

\author{
Isabelle Leblic
}

\section{RÉFÉRENCE}

Éric Lafforgue (avec la collaboration d'Almut Schneider pour les textes), Papous,Paris, éditions Kubic, 160 p., photographies, bibliographie, filmographie.

1 Ce bel ouvrage ${ }^{1}$, organisé en cinq chapitres (Introduction, pp. 12-20, Les préparatifs, pp. 21-52, Cérémonies et danses, pp. 53-82, Portrait de Papous, pp. 83-134, Innovations, pp. 135-157) présente les photographies d'Éric Lafforgue, accompagnées de textes d'Almut Schneider. Ces magnifiques photos ont été faites à Mount Hagen (une des capitales régionales des Hautes Terres de Papouasie Nouvelle-Guinée) à l'occasion du festival culturel annuel ${ }^{2}$ où des centaines de Papous venant des quatre coins du pays, représentant plus de cent groupes différents de danseurs, « richement parés de coiffes de plumes, de peintures faciales ou corporelles et de bijoux en coquillage » (p. 12), se sont présentés. C'est avec beaucoup d'intérêt que l'on apprend que ces festivals, initiés par la puissance colonisatrice australienne (la PNG était sous tutelle de l'Australie jusqu'en 1975). Elle «les [avait] institués dans plusieurs villes afin de développer un sentiment d'unité de la nation au sein de la multitude des peuples papous » avec un succès qui n'a cessé de croître jusqu'à aujourd'hui (p. 12).

Dans l'introduction, Almut Schneider nous présente ce voyage ainsi que le contexte historique de la Papouasie Nouvelle-Guinée, en retraçant les grandes lignes de la découverte mutuelle des Papous et des Australiens. Puis, elle raconte l'origine de ces festivals, depuis une manifestation "organisée [à] Port Moresby par le Papuan Agricultural, Industrial and Cultural Society en 1953 » jusqu'au premier à Mount Hagen en 1964 qui, depuis sont devenus de véritables "événements interrégionaux " qui remportent un succès énorme auprès des Papous eux-mêmes (p. 16), qui permettent la présentation des corps décorés, qui ne sont pas sans rappeler les événements sociaux 
les plus importants que sont ceux qui marquent les étapes de la vie où le signe d'un rituel réussi est justement la présentation du corps dans sa complétude. Ces fêtes sont donc, nous rappelle l'auteur, l'occasion d'affirmer son appartenance à un groupe social car ces fêtes permettent de "monte[r] le nom ", celui du clan, de la tribu... qui «sont sur toutes les lèvres » (p. 17). Et de poursuivre :

«La principale motivation des participants est de montrer une image de leur clan et des membres qui le constituent. Ils apprécient donc énormément d'être pris en photo. L'image photographiée est comme une prolongation de cette représentation d'eux-mêmes, laquelle n'existe en règle générale que de manière éphémère, pendant quelques heures, sur la place cérémonielle. » (p. 17)

Pour cela, Éric Lafforgue nous propose, dans ces clichés, de nombreux gros plans, portraits de Papous parés, mais aussi des scènes de groupes dansants. Ces images magnifiques, tant grâce au talent du photographe que par la beauté des scènes rendues ici, plongent tous les lecteurs ne connaissant pas la Papouasie Nouvelle-Guinée, en plein cœur de ces régions.

4 Dans le premier chapitre, Almut Schneider revient sur les préparatifs nécessaires à ces représentations, la quête des plumes, coquillages et feuillages essentiels à la réalisation des parures... en montrant comment «tout l'environnement naturel des Papous se reflètent [...] dans les corps décorés [de ces] hommes et [de ces] femmes ", que ce soient des éléments des Hautes Terres ou bien originaires du littoral et arrivés jusque-là « en passant de main en main au cours des échanges cérémoniels et grâce aux relations de troc entre les nombreux peuples » (p. 23). Quiconque feuillette cet ouvrage ne peut être que frappé par la profusion de couleurs (des peintures aujourd'hui artificielles, mais hier extraites de pigments naturels comme des parures de plumes) et de dessins qui surgissent au détour des pages et que les photos d'Éric Lafforgue rendent à merveille. Et cette mise en scène du corps embelli est une affaire de groupe, renouvelée à chaque fête car les coiffes de plumes comme les colliers de coquillages sont défaits une fois les réjouissances terminées (p. 24) et de nombreux clichés commentés nous présentent les détails de ces différents éléments de parure et de maquillage et leurs significations.

Le second chapitre nous transporte au cœur des cérémonies et des danses, de ces rituels et échanges cérémoniels qui sont autant d'événements sociaux importants qui montrent la cohésion et l'identité du groupe et dont l'enjeu est le prestige des organisateurs. Ici encore, des clichés splendides de détails, comme ces pieds qu'on a la sensation de voir et d'entendre battre le sol en rythme ou de ces mains frappant les tambours..., d'autres de personnage en entier avec toute leur parure, jusqu'aux photos de groupes de danseurs, les uns figés, comme posant... aux autres pris dans leur mouvement nous immergent dans l'atmosphère qui se dégage, on l'imagine, de ces cérémonies.

6 Dans le troisième chapitre, nous est présentée une magnifique série de portraits d'enfants, de jeunes... ou de "vieux", de femmes ou d'hommes..., où l'identité de chacun est marquée " par un certain maquillage, une coiffe de plumes ou des colliers de coquillages particuliers» (p. 84).

7 Enfin, l'ouvrage se termine sur le renouvellement permanent, preuve de la vivacité de ces cultures.

" "Quand nous changeons, il y a progrès, mais quand ce sont eux [les Papous] qui changent, en particulier pour adopter quelques-unes de nos recettes de progrès, on dit que c'est une perte de culture", constate l'anthropologue Margaret Jolly. » (p. 136) 
Rien de plus juste en effet et que illustrent donnent à voir l'émergence de nouvelles troupes de danses contemporaines tels que les «hommes squelettes» (p. 138 sq.) ou l'intégration dans les parures d'éléments allogènes tels que des clés, une pièce de compteur électrique, des décorations de Noël ou encore des photos placées sur les coiffes... Cet ouvrage, que l'on classe sans conteste dans la catégorie des beaux livres, avec une mise en plage particulièrement soignée et une belle qualité de papier et d'impression, nous donne donc à voir, avec splendeur, la diversité de ces cultures dans leur dynamique. Un ouvrage à recommander pour un public des plus larges, s'intéressant autant à la Papouasie Nouvelle-Guinée qu'à la photographie.

\section{NOTES}

1. Ce livre n'est pas sans nous rappeler, par certains côtés, celui aux portraits étonnants de Malcom Kirk (pour les photographies) et Andrew Strathern (pour le texte) publié en 1981 par The Viking Press (New York) et traduit en français la même année sous le titre Les Papous. Peintures corporelles, parures et masques (Paris, Chêne/Hachette) et signalé par ailleurs par Almut Schneider et Érice Lafforgue en bibliographie.

2. NDLR. «Il faut signaler que ce type de festival, auquel j'ai assisté il y a longtemps, se déplaçait d'une année sur l'autre entre Mount Hagen et Goroka» (Godelier, com. person., information signalée également par Pascale Bonnemère). Voir aussi l'ouvrage publié en 1971 par Andrew et Marilyn Strathern, Self-decoration in Mount Hagen (édité chez Duckworth), qui était,semble-t-il, le premier livre montrant la manière dont les habitants de Papouasie Nouvelle-Guinée se décoraient précisément pour le festival de Mount Hagen.

\section{AUTEURS}

\section{ISABELLE LEBLIC}

CNRS - LACITO à Villejuifleblic@vjf.cnrs.fr 